Distribution Category:

Fluidized Bed Combustion

(UC-103)

ANL/FE-89/4

ANL/F'E--89/4

DE91 004944

\begin{abstract}
Argonne National Laboratory
9700 South Cass Avenue

Argonne, Illinots 60439
\end{abstract}

\title{
DEVELOPMENT OF A HIGH-TEMPERATURE EROSION MONITOR FOR FBC HEAT EXCHANGER TUBES
}

by

Karl J. Reimann

Materials and Components Technology Division

May 1990

Work supported by

the U.S. Department of Energy, Morgantown Energy Technology Center 


\section{CONTENTS}

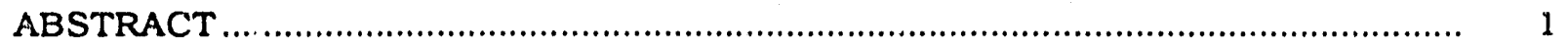

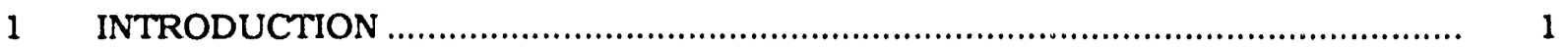

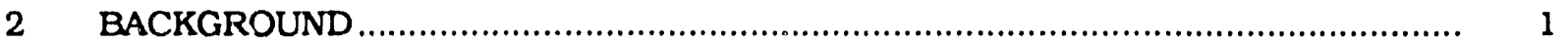

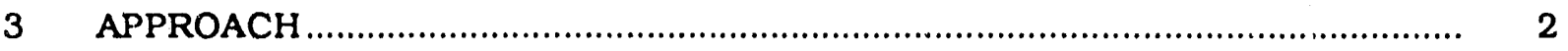

3.1 Evaluation of Transducers ..................................................................... 2

3.1.1 Electromagnetic Acoustic Transducers........................................ 3

3.1.2 Piezoelectric Transducers................................................................... 5

3.2 Assessment of High-temperature Cable .................................................. 7

3.3 Development of Damping Block ............................................................... 7

3.4 Development of Bonding Technique ............................................................ 7

3.4.1 Dry Pressure-coupling ........................................................... 9

3.4.2 Bonding with High-temperature Cements..................................... 9

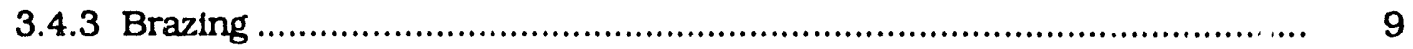

4 PROTOTYPE PERFORMANCE ................................................................... 10

5 DISCUSSION AND CONCLUSIONS........................................................... 15

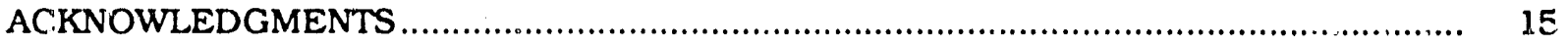

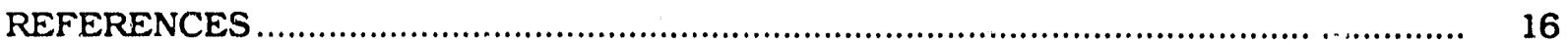

\section{FIGURES}

1 Measurement of Wall Thickness of Sample FBC Heat-Exchanger

Tubing from the Outside with an EMAT.

2 Trace of Multiple Echoes Obtained with the EMAT Shown in Fig. 1 .................. 4

3 Experimental EMAT for Bore-side Wall-thickness Measurement................... 4

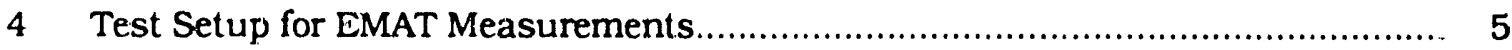

5 Trace of Multiple Echoes Obtained with 5-MHz Commercial

Piezoelectric Transducers on Outside of tube

6 Reflections from Braze between Insert and Tube Obtained with Commercial 5-MHz Transducer.

$7 \quad$ Reflections as in Fig. 6, with Lithium Niobate Crystal. Damping Block, and Ultrasonic Couplant 
8 Arrangement for Brazing Crystal to Shoe inside Sample Tubing ..................... 8

9 Brazed-Crystal Response from a Stainless Steel Cylinder; No Damping Block... 11

10 Response of Same Crystal as in Fig. 9, after Grinding One Crystal Surface Concave; No Damping Block.................................................... 11

11 Diagram of Pressure Coupling Arrangement ......................................... 12

12 Prototype Used in Temperature Experiments ......................................... 13

13 Backwall Reflection of Pressure-coupled Transducer at $21^{\circ} \mathrm{C} \ldots \ldots \ldots \ldots \ldots \ldots \ldots \ldots . . . . . . . . .13$

14 Backsvall Reflections of Pressure-coupled Transducers at $518^{\circ} \mathrm{C} \ldots \ldots \ldots \ldots \ldots \ldots . . . . . .14$

15 Measured Ultrasonic Velocity Changes as a Function of Temperature for Various Metals ............................................................................... 15

TABLE

1 Parameters of Wall Thickness Measurements ....................................... 14 


\title{
DEVELOPMENT OF A HIGH-TEMPERATURE EROSION MONITOR FOR FBC HEAT EXCHANGER TUBES
}

by

Karl J. Reimann

\begin{abstract}
Metal wastage in tubing of heat exchangers used in fluidized bed combustion (FBC) could affect plant operation and threaten the successful development of $\mathrm{BC}$ technology.

Monitoring of such wastage during operation would be very beneficial. The development of a high-temperature erosion monitor was undertaken as part of a larger program to understand and amellorate wastage processes.

Two sensor principles, 1.e., electromagnetic acoustic and piezoelectric transducers based on time-of-flight measurements, were evaluated. Spatial restrictions and high-energy requirements of electromagnetic acoustic iransducers favored piezoelectric transducers as a prototype. Requirements for good coupling between sensor and tubing led to the exploration of two methods for accomplishing this task: pressure coupling and brazing. Initial disappointments with brazing led to the construction of a pressure-coupled transducer that was tested successfully to temperatures of up to $500^{\circ} \mathrm{C}$. A brazing method to bond the lithlum niobate crystal to stainless steel was finally perfected, but will require additional work for brazing to ferritic steel. The prototype pressure-coupled transducer also needs more development to compensate for the expansion of components and oxidation of coupling surfaces.
\end{abstract}

\section{INTRODUCTION}

Metal wastage of in-bed heat-exchanger surfaces is a serious problem in the development of nuidized bed combustion (FBC) technology. A project presenting a systematic approach to developing the necessary understanding of the wastage process and formulating guidelines for the design and operation of FBC units was undertaken by the U.S. Department of Energy (DOE) and a consortium of other organizations. One task of the overall project addressed the development of an erosi n monitor to provide in-situ measurement of erosion in FBC plants. The envisioned on-line system wotild be capable of monitoring erosive wear of the fireside (outer) surface of heat-exchanger tubes in FBC systems. The heat-exchanger geometry and operating conditions require the use of one or more boreside sensors capable of long-term operation at temperatures up to $500^{\circ} \mathrm{C}$ and occasional excursions to higher temperatures. The boreside dimensions of the heat-exchanger tubes $(\sim 1.75$-in. 1.d.) determine the size of the sensors; the desired measurement accuracy and repeatability should be as high as attainable.

\section{RACKGROUND}

Erosive wear of FBC heat exchangers is produced by energetic solid particles of fuel and sorbent in the fluidized gas stream impinging on the outer surface of metal tubing containing the heat-transfer fluid (ivater, steain, or air). Locations on the heat exchangers where erosion is most severe can be approximately specified from past observations, from inspection after some wear has been experienced, or prospectively, from computer modeling. Erosive wear gained renewed attention with operaition of coal conversion pilot plants. Argonne National Laboratory (ANL) became engaged in the development of a nondestructive metal wastage monitoring system for metallic process lines and vessels. ${ }^{1}$ An automatic ultrasonic surveillance system, based on ultrasonic time-of-flight measurements, was developed and 
installed in several coal-liquefaction and coal-gasification pllot plants. The system, which precisely assessed wall thickness of process components during plant operation, incorporated conventional ultrasonic transducers that were thermally insulated by specially designed acoustic waveguides attached to a specific point on the outside of the components of interest. Utilization of waveguides was feasible since the wastage occurred on the inside surfaces. Many transducers and waveguides were employed when a wastage profile was desired. The transducers were scanned sequentially from a remote, centralized instrument station, and the ultrasonic responses were automatically converted to indicate the remaining wali thicknesses at the monitored points, taking into account dimensional and ultrasonic velocity changes as a function of temperature. Precise measurements of \pm 2 mil $(0.05 \mathrm{~mm})$ were typically achieved with steady temperatures.

The successful implementation of waveguides for erosion monitoring in pilot plants motivated a study of electromagnetic acoustic transducers (EMATs) ${ }^{2}$ for use as ultrasonic transducers for erosion monitoring. The main advantage of the EMAT was that no couplant or permanent attachment to the monitoring points was required and an erosion proflle could be obtained with a single-scanning transducer. The study showed that, with water cooling. EMATs could be applied to measure wall thicleness from the outside to temperatures up to $500^{\circ} \mathrm{C}$. However, there were some drawbacks to transducers of this type. They required a higher input power than piezoelectric transducers, had lower signal-to-noise $(\mathrm{S} / \mathrm{N})$ ratios, and operated only on metallic materials.

The experience gained from monitoring of material wastage on the inner surface of components was helpful in defining the approach to the problem of erosion measurements from the bore-side of FBC heat-exchanger tubing. ${ }^{3}$ Previous monitoring-system components, such as automatic gain control transmitters/recetvers, sequential switching systems, and computer interfaces with temperature-correction software, could be used without significant modification. Other components, especially the transducer, required signilicant development effort; conventional off-the-shelf, high-temperature transducers that could operate in the required temperature range were not avallable.

\section{APPROACH}

Implementation of piezoelectric ultrasonic transducers for wall-thickness measurement from the bore-side of tubing called for a piezoelectric material with a Curle temperature above $500^{\circ} \mathrm{C}$, a damping material that could withstand that temperature, and a bonding method (to attach the crystal to the tubing wall and the damping block) that would yield a good ultrasonic coupling at the required temperature. A high-temperature-resistant coaxial cable to connect the transducer to the ultrasonic pulser/recetver was also necessary. In addition, to adapt the previously investigated prototype EMAT for use in the tube bore, it was necessary to reduce its size drastically.

\subsection{Evaluation of Transducers}

Both types of ultrasonic transducers, plezoelectric and electromagnetic acoustic, were successfully tested for erosion monitoring of the inside surface of piping and coal-conversion components. Monitoring of FBC heat exchanger tubing from the boreside imposed more severe requirements on the transducers. 


\subsubsection{Electromagnetic Acoustic Transducers}

Measurements of wall thickness were conducted on pieces of tubing removed from the Georgetown Untversity FBC heat exchanger. A flat-surface, shear-wave EMAT with a permanent magnet for the static field was applied to the outside surface of the sample tubing [wall thickness of $0.132 \mathrm{in}$. $(3.35 \mathrm{~mm})$ ]. Figure 1 shows the EMAT used in these preliminary tests. Figure 2 displays the ultrasonic multiple echoes from the wall. The elapsed ime between successive echoes was $2.1 \mu \mathrm{s}$, which, with an ultrasonic shear-wave velocity of $3.19 \times 10^{3} \mathrm{~m} / \mathrm{s}$. yields a wall thickness of $3.35 \mathrm{~mm}(0.132 \mathrm{in}$.). Implementation of an EMAT for wall-thickness mizasurements would be advantageous since no couplant is required. This enables operation of a transducer in a scanning mode to pinpoint areas of maximum erosion. There were, however, problem areas. Permanent magnets could not be used at elevated temperatures. An electromagnet in place of a permanent magnet would lose efficiency at elevated temperatures due to a pronounced decrease in yoke permeability. High currents would be necessary to generate a stronger static field in an air-core coll. The whole transducer assembly, moreover, would have to fit inside the tube bore.

A 24-VDC, 140-W relay coll with soft iron core was initially used as the static-field coil. A pancake coll of 50 turns was implemented as the RF coll (Fig. 3). Avallable power supplies were used to energize the static-field coll with DC ranging from $200 \mathrm{~mA}$ to $1 \mathrm{~A}$. The test setup for the RF transmitting/recetving coll is shown in Fig. 4. It consisted of a

Fig. 1.

Measurement of Wall Thickness of Sample FBC Heat-Exchanger Tubing from the Outside with an EMAT

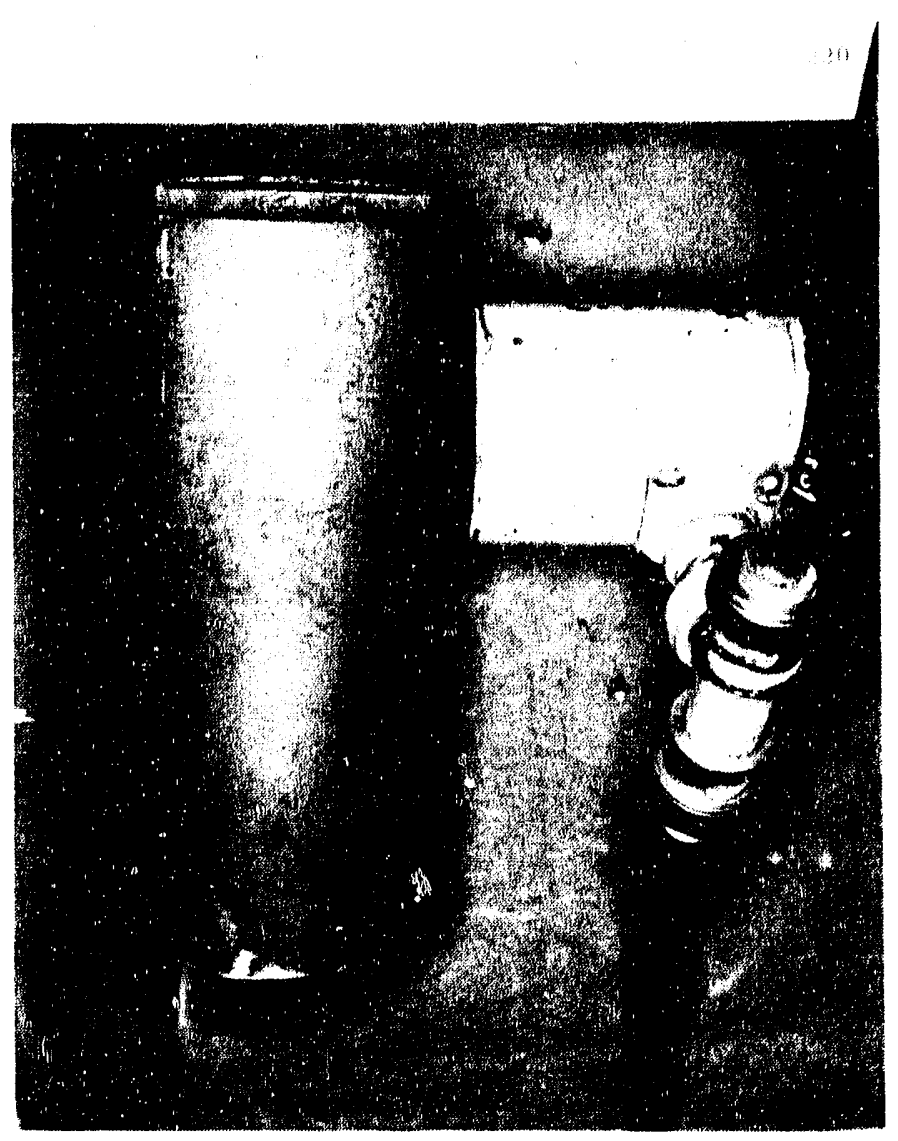


Fig. 2.

Trace of Multiple Echoes Obtained with the EMAT Shown in Fig. 1 Vertical scale: $0.1 \mathrm{~V} / \mathrm{DW}$

Horizontal scale: $0.56 \mu s / D i v$
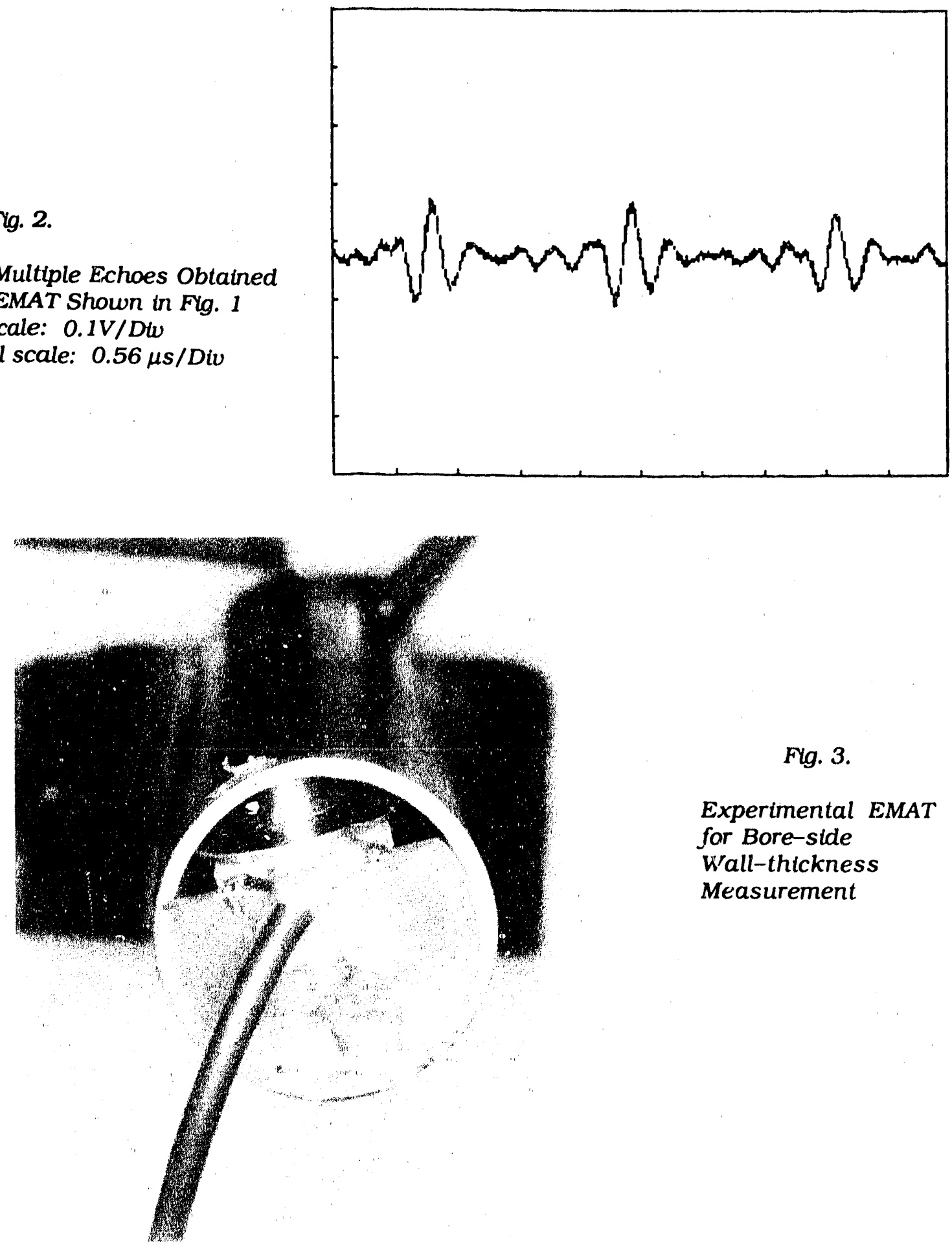

Fig. 3.

Experimental EMAT for Bore-side Wrall-thickness Measurement 


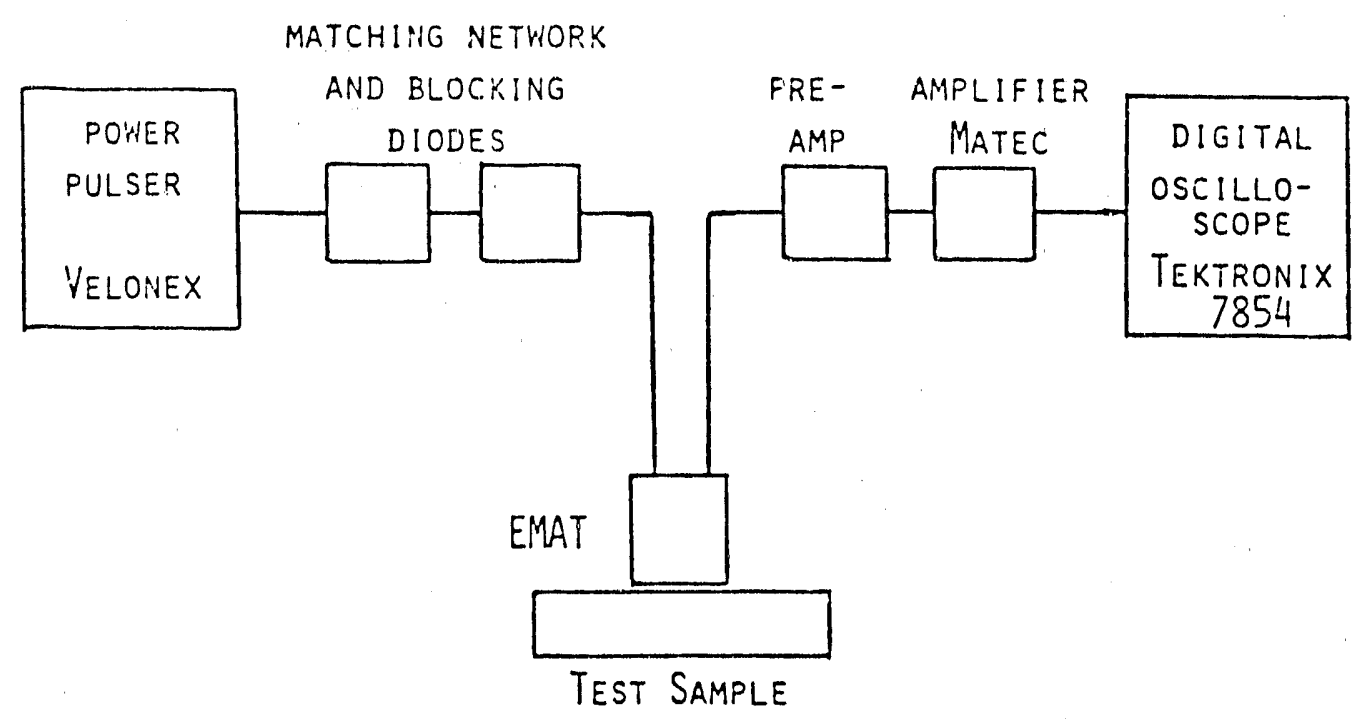

Fig. 4. Test Setup for EMAT Measurements

pulsed-power oscillator (to supply 1000-V peak power to the RF coll of the EMAT), a recetver with $95 \mathrm{~dB}$ gain, and an oscilloscope. The performance of the prototype bore-side EMAT was evaluated on sample tubing and nat specimens and compared with the performance of the permanent-magnet EMAT (shown in Fig. 1). No discernible ultrasonic echoes were obtained from the wall of the sample tubing or flat specimens. Detalled investigation of the performance of the RF pancake colls of both EMATs, with electromagnetic-field measurement and a small coll, showed that the RF colls performed equally well in both EMATs. Measurement of the static field with a Hall probe showed that it was one magnitude higher at the EMA'T with the permanent magnet than with the prototype boreside unit ( 270 gauss versus 24 gauss at $200 \mathrm{~mA}$ ). A difference of one magnitude in the static field results in a difference of two magnitudes in signal amplitude.

Different colls, pole-plece sizes, and DC amplitudes were tested to increase the magnitude of the static field, with limited success. Small pole pleces resulted in saturation (at 100 gauss), whereas air colls required very high current to sufficiently increase the field ( 5000 ampere turns). The high current would require pulsed operation of the static field and cooling provisions. The low frequency of the EMATs $(>5 \mathrm{MHz})$ required high-pass filtering to obtain the desired temporal resolution. In general, EMATs, are $60 \mathrm{~dB}$ less efficient at generating and receiving ultrasonic waves than plezoelectric ultrasonic transducers. Piezoelectric. transducers, moreover, are smaller. These difficulties with EMATs led to the selection of piezoelectric ultrasonic transducers as more viable sensors for erosion monitoring.

\subsubsection{Piezoelectric Transducers}

The wall thickness of the sample tubing was ultrasonically measured from the outside of the tube with a commercial 5-MHz, 0.5-in.-o.d. gamma transducer. The transducer generated longitudinal waves with a velocity of $5.9 \times 10^{3} \mathrm{~m} / \mathrm{s}$ in the tube material. Multiple tube-wall echoes are shown in Fig. 5. The time lapse between successtve echoes is $1.1 \mu \mathrm{s}$, from which a wall thickness of $3.25 \mathrm{~mm}(0.128 \mathrm{in}$.) was calculated. A shoe of ferritic sterl was silver brazed, in a vacuum of $10^{-4}$ Torr, to the inside wall of the sample tubing to match the flat transducer to the tube radius. The vacuum brazing of the shoe resulted in a reflection from the braze and from the outside tube wall, as shown in Fig. 6 . The tube-wall thickness was calcillated from the two ultrasonic way'e reflections and served to monitor the erosion losses. 
Fig. 5.

Trace of Multyle Echoes Obiained with 5-MHz Commercial Plezoelectric Transducers on the Outside of the Tube. Vertical Scale: $0.2 \mathrm{~V} / \mathrm{Dw}$; Horizontal Scale: $0.5 \mu \mathrm{s} / \mathrm{Dw}$
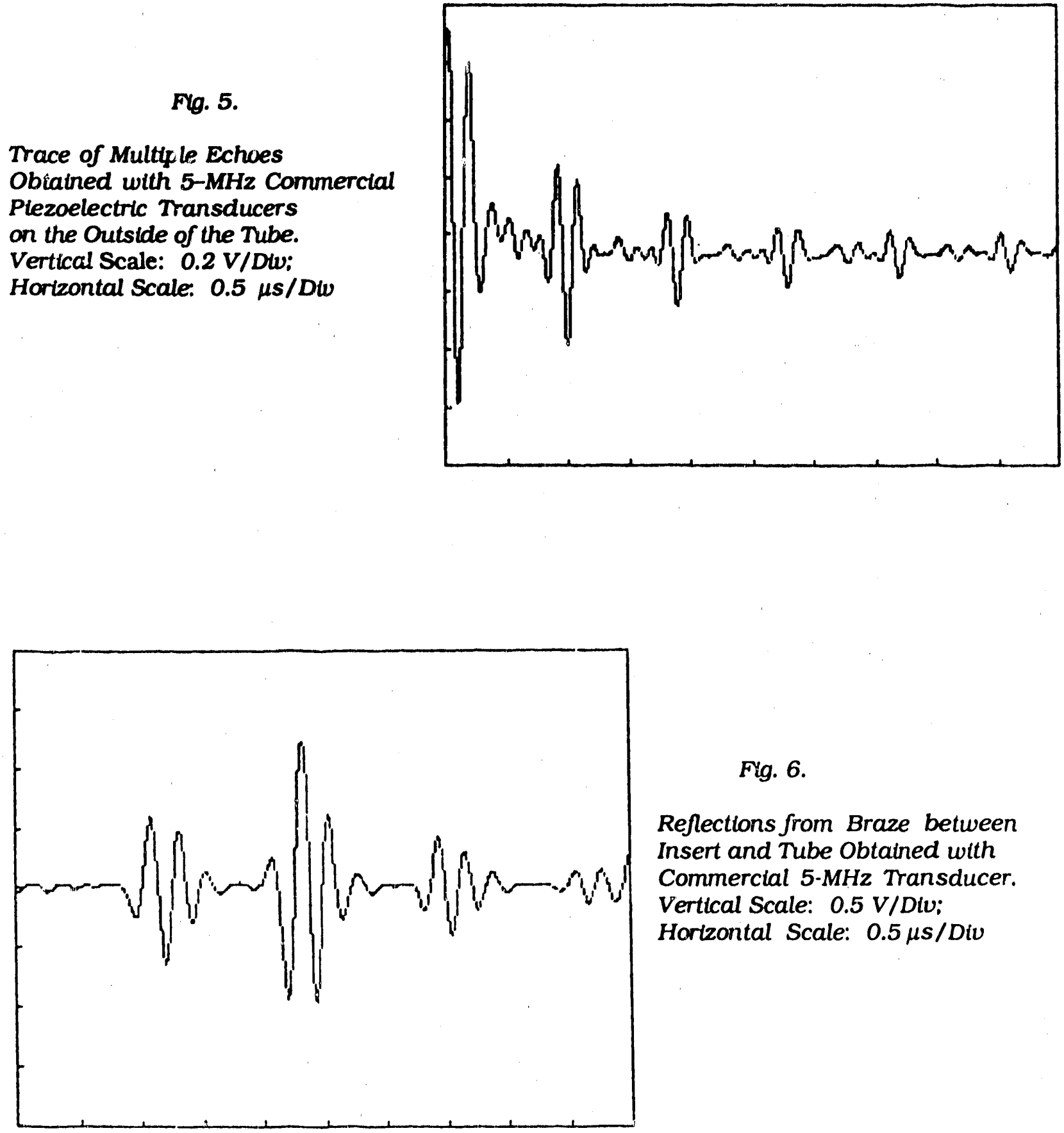

Fig. 6.

Reflections from Braze between Insert and Tube Obtained with Commercial 5-MHz Transducer. Vertical Scale: $0.5 \mathrm{~V} / \mathrm{Div}$ : Horlzontal Scale: $0.5 \mu \mathrm{s} / D i v$ 
High-temperature operation of the erosion sensors necessitated the selection of a high-Curie-temperature plezoelectric crystal such as lithlum niobate and the procurement of a high-temperature ultrasonic damping material. The damping component in commerclal ultrasonic transducers is made from epoxy that contains high concentrations of tungsten powder.

A 5-MHz lithium niobate crystal was tested in the sample tubing with a sintered aluminum-tungsten powder cylinder as the damping member. The crystal was coupled to the shoe and damping block with an ultrasonic coupling gel. Ultrasonic echoes of this arrangement are shown in Fig. 7. The results indicate that the desired features covld be attained with proper coupling. A solid, ultrasonically transparent bonding was necessary for high-temperature application. Crystal brazing or high-temperature cement proved to be the most logical bonding methods. The damping block would have to be fabricated of different matrix material than aluminum for high-temperature applications. The crystal brazing assembly is shown in Fig. 8.

\subsection{Assessment of High-temperature Cable}

High-temperature cables with single or multiple conductors are commercially avallable (e.g., from GMI of Addison, IL). Single-conductor, stainless-steel-sheathed coaxial cable with magnesium oxide insulation was obtained and tested at room temperature in conjunction with a $5-\mathrm{MHz}$ commercial transducer. The cable had an o.d. of $4.76 \mathrm{~mm}(3 / 16 \mathrm{ln}$.) and a capacitance of $1 \mathrm{nF} / \mathrm{m}$. Commercial coaxial transducer cables (Type RG-174/V have a capacitance of 100 $\mathrm{pF} / \mathrm{m}$. The ultrasonic driving and reflection echo pulses were identical for the hightemperature and standard coaxial cable at room temperature. The high-temperature coaxial cable was therefore judged as applicable for erosion monitoring. The manufacturerrecommended temperature range for these cables extends to $2000^{\circ} \mathrm{C}$.

\subsection{Development of Damping Block}

The sintered aluminum-tungsten damping component for the transducer exhibited the desired properties but posed potential bonding problems. Copper was selected as an alternate matrix material for the damping component. Three compositions of copper-tungsten (15-, 30-. and $45-w t . \%$ tungsten) were prepared by powder metallurgy processes and sintered for $1 \mathrm{~h}$ at $810^{\circ} \mathrm{C}$ in vacuum. Damping propertles were subsequently determined by ultrasonic ampl!t" ide measurements in the pulse-echo and through-transmission modes. The results indicate that the 45-wt.\% tungsten damping cylinder would attenuate ultrasonic waves one order of amplitude $(20 \mathrm{~dB})$ higher than the block with $15-$ wt.\% tungsten; therefore, it had the best damping properties. The damping block was subsequently tested in the sample tubing with a 5-MHz lithium niobate crystal and ultrasonic gel couplant. The trace of the signal was identical to that shown in Fig. 7, qualifying it for incorporation into the high-temperature sensor.

\subsection{Development of Bonding Technique}

A plezoelectric sensor requires good coupling between the crystal and the specimen in order to properly operate as a generator/recelver of ultrasonic vibrations. To achleve good coupling, commercially available couplants are used at room and slightly elevated temperatures. There is, however, no couplant on the market that sustains the coupling properties at prolonged exposure to $500^{\circ} \mathrm{C}$ or temperature cycling near this temperature. Three approaches to developing other coupling methods for the erosion monitor were explored: (1) dry pressure-coupling. (2) bonding with high-temperature cements, and (3) braing with sultable materials. 
Fig. 7.

Reflections as in Fig. 6 , with Lithium Niobate Crystal. Damping Block, and Ultrasonic Couplant. Vertical Scale: $0.5 \mathrm{~V} / \mathrm{Div}$; Horizuntal Scale: $0.5 \mu \mathrm{s} / D \mathrm{w}$
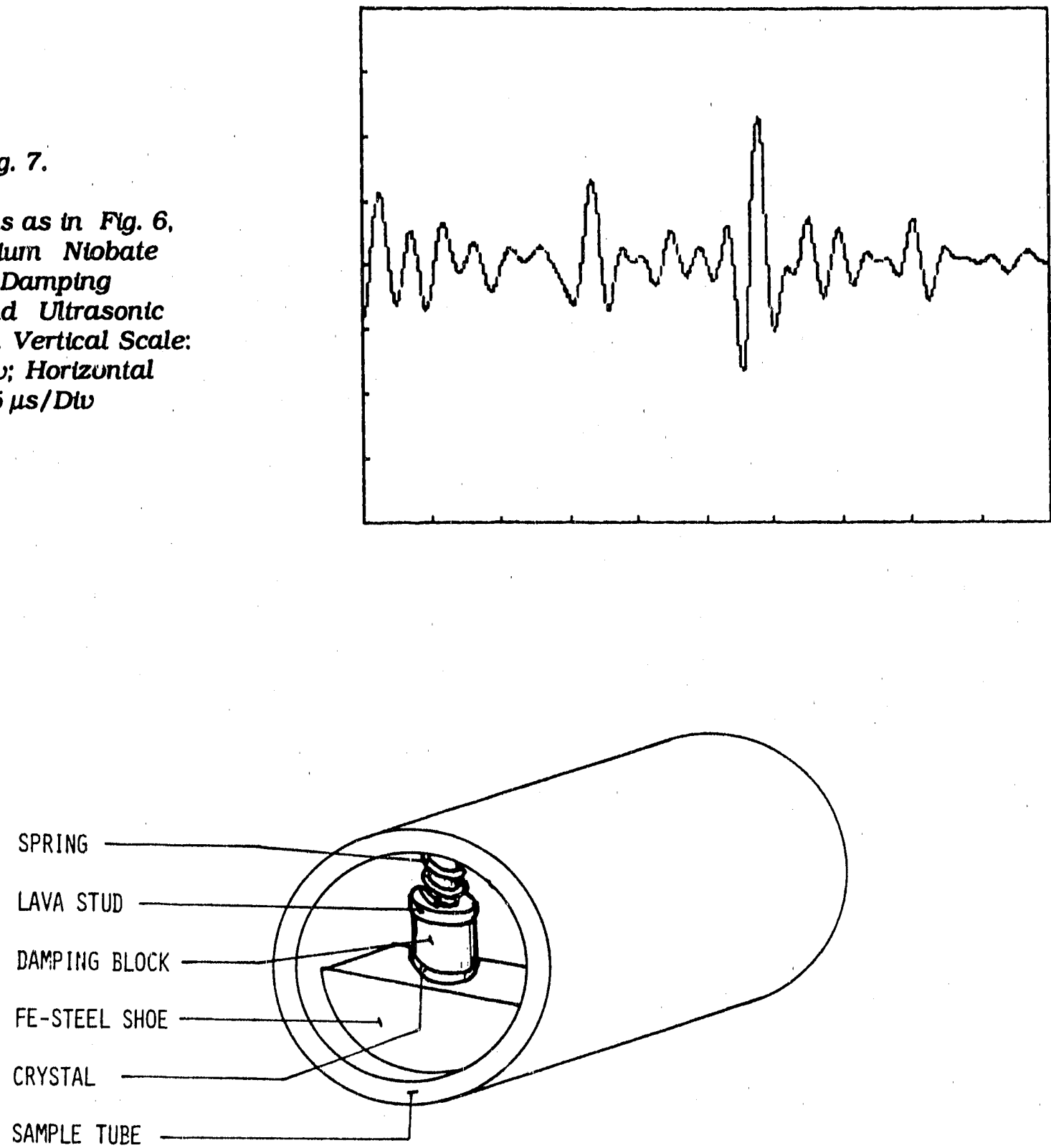

Fig. 8. Arrangement for Brazing Crystal to Shoe inside Sample Tubing 


\subsubsection{Dry Pressure-coupling}

A special yoke was designed and built to facilitate dry coupling on flat, ferritic steel specimens of approximately the same thickness as the sample-tube wall The materials used for the dry couplant included: 0.5-mil and 3-mil aluminum foll, 3-mil gold foll, and yttrium chromite in both fine powder and slurry form. Pressure was applied by tightening the bolts with a torque wrench to a maximum of $5000 \mathrm{Nm}(3690 \mathrm{lb} / \mathrm{ft})$. The couplant was applied on both faces of the crystal. Two types of surfaces on the flat specimens were tested: one flattened on a grinder and the other highly polished by 300 -grit abrasive. The best coupling was achieved with the 0.5-mil aluminum foll, although it was still inferior to ultrasonic gel couplant. The polished surfaces exhibited slightly better coupling than the ground surfaces. In all cases, the crystal was cracked by the high-pressure forces needed for coupling. The required coupling pressure would impose problems at $500^{\circ} \mathrm{C}$ operation because of elongation, distortion, anc' loss of pressure.

\subsubsection{Bonding with Figh-temperature Cements}

Two high-temperature cements, Sauereisen and Omega, were used to attach the crystal to the specimen and damping block. Although the mechanical bond was good, ultrasonic performance of the samples was poor, 1.e., very little ultrasonic energy could be introduced into or received from the specimen. Closer examination revealed that small bubbles developed. during the curing process and the coupling layer became very porous, thus srattering ultrasonic energy. Both cements attacked the surface of the flat ferritic steel sample and the damping block. These high-temperature cements were deemed unsuitable for bonding.

\subsubsection{Brazing}

The joining of ceramic parts to metal by brazing has found wide application in industry. It is a more difficult process, however, when the ceramic is a single crystal such as lithium niobate. Different brazing materials, processes, and crystal-surface preconditioning were evaluated. To prevent crystal damage, the manufacturers of lithium niobate crystals recommend slow heat-up and cool-down times $\left(\max .200^{\circ} \mathrm{C} / \mathrm{h}\right.$ ) for such operation.

As a first approach, 1-mil-thick braze shim material (Braze No. 603/604 AWS A5.8.B Ag-18 by Handy and Harman) was sandwiched between the crystal and shoe in the sample tubing and between the crystal and damping block to simultaneously effect brazing of both components. Brazing was performed in a vacuum of $10^{-6}$ Torr at $660^{\circ} \mathrm{C}$. The assembly was maintained at this temperature for $15 \mathrm{~min}$ before cool-down. Heating and cooling rates were $200^{\circ} \mathrm{C} / \mathrm{h}$. The crystal had sputtered platinum electrodes on both surfaces. This brazing operation resulted in satisfactory mechanical bonding between the crystal and the ferritic shoe, but no bonding to the damping block. Because the crystal moved "off center" during brazing, the ultrasonic quality of the bond could not be assessed.

The same brazing operation was repeated, under identical condilions, using a crystal with thicker blas-sputtered platinum electrodes and evaporated gold electrodes. These brazing operations caused lift-off and dissolution of the electrode materials without bonding.

Lucanex 559 brazing paste (manufactured by Lucas-Milhaupt, Inc.), was used in subsequent experiments. The optimum brazing temperature for this paste is $925^{\circ} \mathrm{C}$ : a minimum pressure of $10^{-4}$ Torr is recommended for the vacuum (or inert gas) brazing procedure. This paste was deposited as crystal electrodes by air brazing and resulted in good adherence to the crystal with no metallic appearance. Vacuum brazing of two copper cyinders. one on either side of the crystal, resulted in good bonding. Ultrasonically, the cylinders provided low damping and therefore long ring-down time. 
The vacuum brazing operation was repeated with a crystal and damping block placed on the shoe of the samnle tubing, resulting in a good bond between the crystal and damping block. but a poor bond between the crystal and the shoe in the sample tubing. The copper in the damping block appeared to enhance bonding to the crystal during vacuum brazing. The lithium niobate crystals discolor when heated in vacuum because of the internal migration of ithlum atoms. The process can be reversed by reheating the crystal in air or axygen.

In 1988, investigators in Frarice successfully developed process sensors by brazing lithlum niobaic to titanium with a DuPont conductive paste. This paste, a platinum/silver condinctor composition (DuPont No. 9770), was acquired and tested. A crystal with sputtered electrodes was atr brazed at $850^{\circ} \mathrm{C}$ to a stainless steel cylinder. A very strong mechanical bond resulted and showed good ultrasonic properties. Due to the lack of damping, the transducers had a long ring-down time, as shown in Fig. 9. A procedure similar to that implemented by the French investigators was applied to increase the damping properties of the crystal. The nonbonded surface of the crystal was ground concave with a radius of $75.7 \mathrm{~mm}(2.98 \mathrm{in}$.), equal to a diopter of 7.00. Grinding the crystal broadened its frequency spectrum, thus effectively introducing more damping, as shown in Fig. 10. A very thin layer $(>200 \AA)$ of gold was evaporated onto the stainless steel cylinder prior to the air brazing to protect the surfaces from oxidation.

In a subsequent trazing experiment, a crystal ground concave on one surface was air brazed to the shoe in a sample tube. The ferritic shoe material oxidized heavily during the brazing operation because no protective layer of gold was applied. While the flow of the brazing material was very uniform, it lifted off after cocling, forming a layer of scale during brazing. The same result occurred when attempting to braze a crystal to a copper cylinder representing a damping block. It is evident that for air brazing with DuPont paste 9770 , the components must be coated with some nonoxidizing material such as a noble metal.

\section{PROTOTYPE PERPORMANCE}

Initial difficulties encountered in brazing lithium niobate crystals to ferritic steel components caused renewed interest in pressure coupling. An assembly, shown in Figs. 11 and 12. was designed and constructed. The tungsten-copper damping block, which was destroyed in one of the brazing experiments, was replaced by a tungsten-filled Sauereisen cement block. The assembly was placed in an oven and the temperature was increased slowly to $-500^{\circ} \mathrm{C}$. Temperature measurements were performed with a chromel-alumel thermocouple and an "Omegaternip" digital-readout instrument. The assembly was kept at each set temperature (every $100^{\circ} \mathrm{C}$ ) for $0.5 \mathrm{~h}$ to allow for equilibration. The expanded ultrasonic signal was recorded at every $100^{\circ} \mathrm{C}$ interval, and the elapsed time was registered. Figures 13 and 14 show the ultrasonic reflections at $21^{\circ} \mathrm{C}$ (room temperature) and at $518^{\circ} \mathrm{C}$, respecttvely. Table 1 lists the elapsed times, ultrasonic velocities, and calculated wall thicknesses. The ultrasonic velocities were extrapolated from the 2-1/4 $\mathrm{Cr}-1$ Mo data shown in Fig. 15.

As shown in Table I, the wall thicknesses measure within \pm 1 mil when ultrasonic velocity variations are corrected as a function of temperature. The following observations were made during the temperature test run: (1) the coupling deteriorated with temperature, owing to expansion: (2) the pressure screws had to be tightened at $\sim 300^{\circ} \mathrm{C}$ to restore the coupling and obtain a signal with adequate S/N ratio; and (3) the response after cool-down to room temperature exhibited a higher nolse level than before the temperature test run, probably owing to partial axddation of the contact surfaces. It is evident that pressure coupling is a viable solution to the erosion monitor design, but some modifications need to be implemented to overcome some of the shortcomings encountered in the prototype model. 


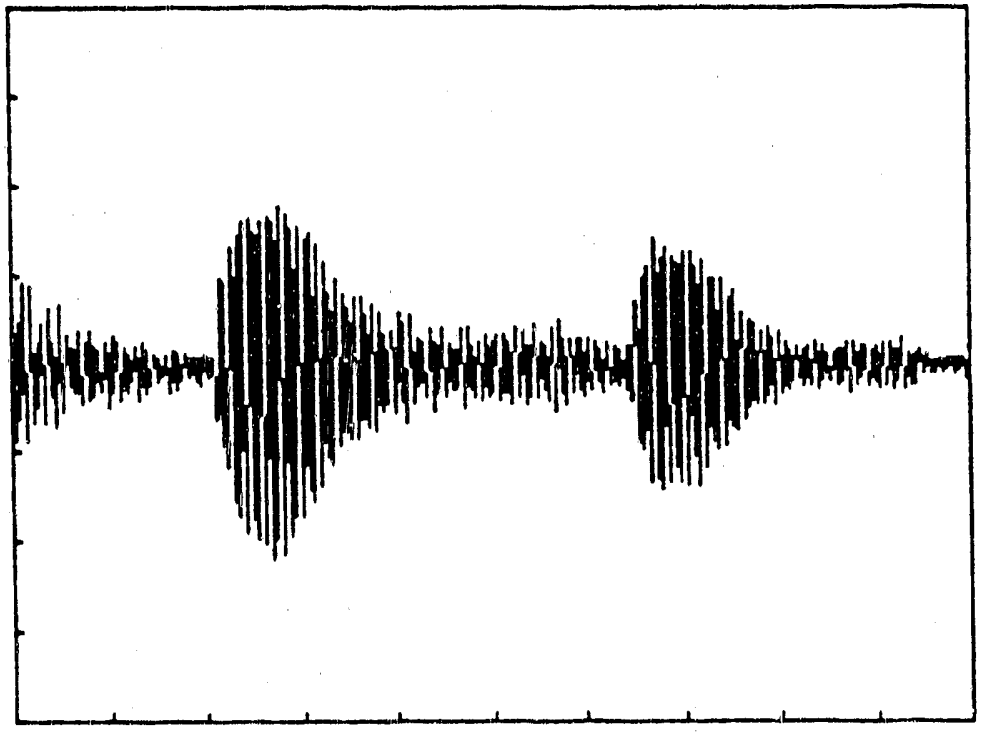

Fig. 9.

Brazed-Crystal Response from a Stainless Steel Cylinder; No Damping Block

Fig. 10.

Response of Same Crystal as in Fig. 9, after Grinding One Crystal Surface Concave; No Damping Block

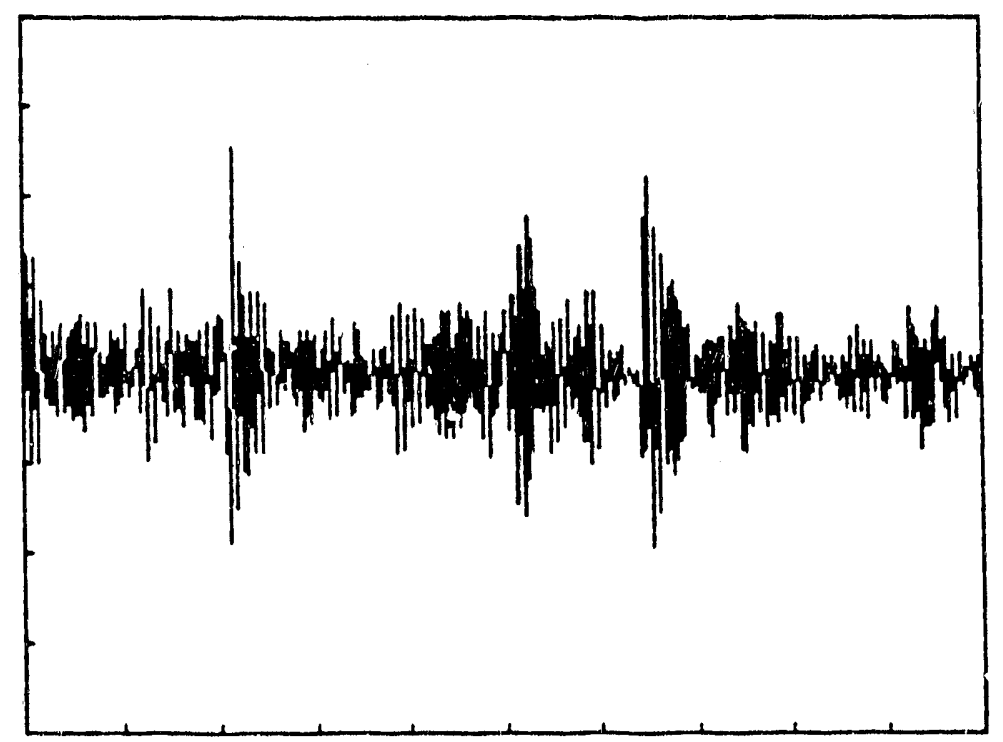




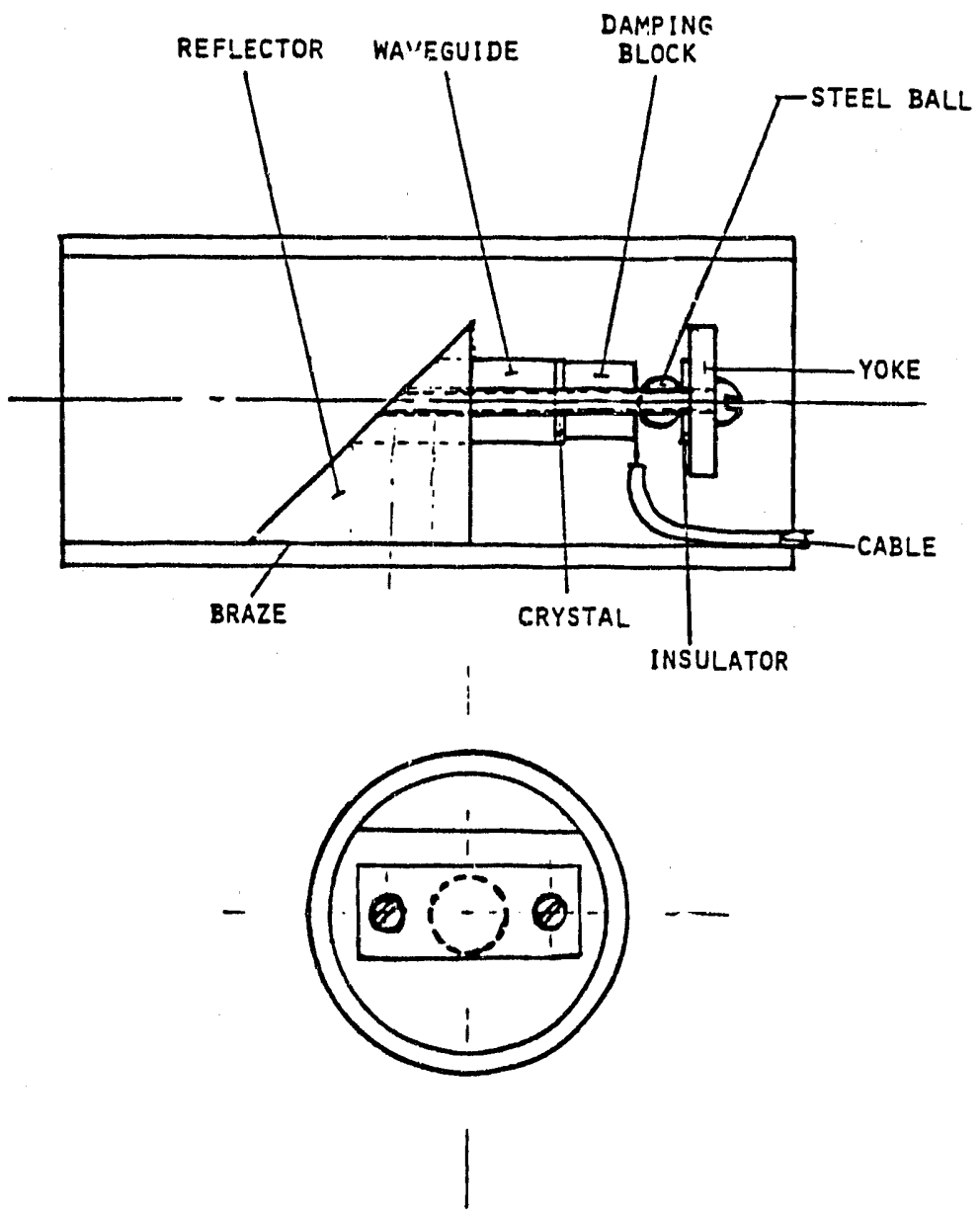

Fig. 11. Dlagram of Pressure Coupling Arrangement 


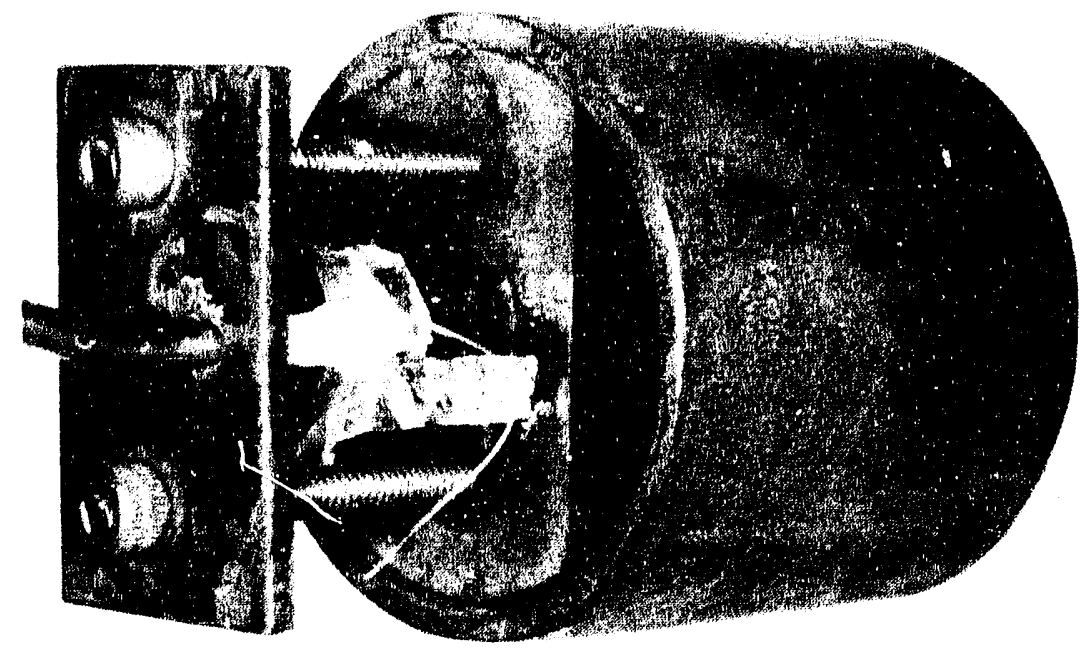

Fig. 12. Prototype Used in Temperature Experiments

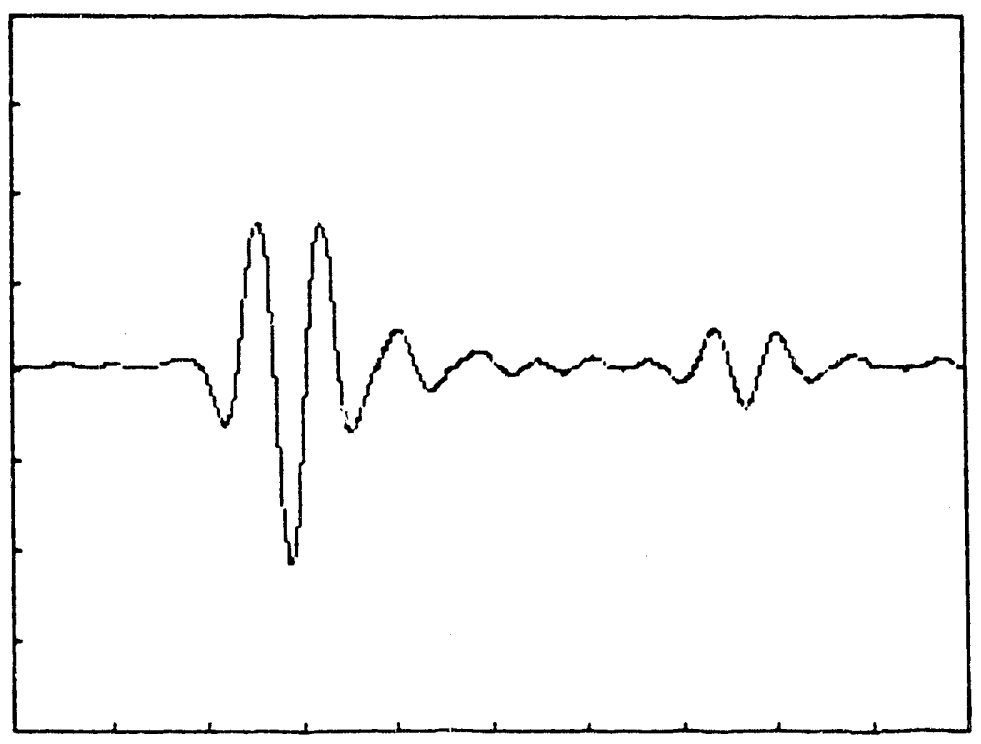

Fig. 13.

Backwall Reflection of Pressure-coupled Transducer at $21^{\circ} \mathrm{C}$ 


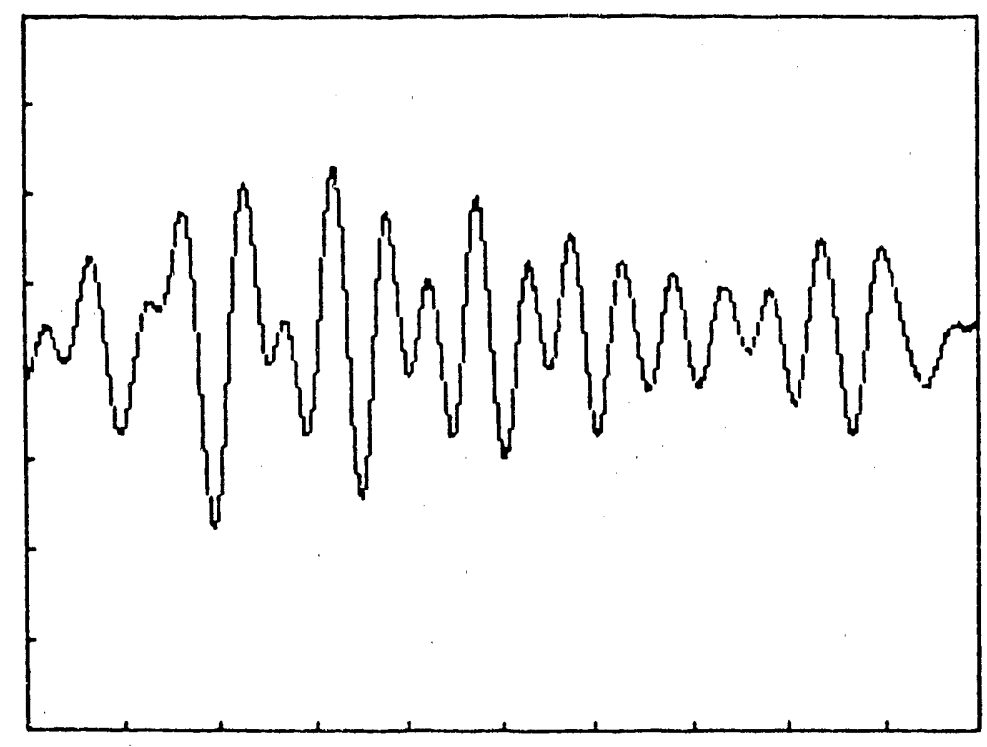

Fig. 14.

Backwall Reflections of Pressure-coupled Transducers at $518^{\circ} \mathrm{C}$

Table 1. Parameters of Wall Thickness Measurements

\begin{tabular}{rllll}
\hline $\begin{array}{c}\text { Temp., } \\
{ }^{\circ} \mathrm{C}\end{array}$ & $\begin{array}{c}\text { Elapsed } \\
\text { Time, } \\
10^{-6}\end{array}$ & $\begin{array}{l}\text { Ultrasonic } \\
\text { Velocity, } \\
10^{5} \mathrm{~cm} / \mathrm{s}\end{array}$ & \multicolumn{2}{c}{ WallThickness } \\
\hline & & & & $\mathrm{mm}$ \\
22 & 0.982 & 5.94 & 115 & 2.92 \\
105 & 0.984 & 5.90 & 114 & 2.90 \\
204 & 0.998 & 5.84 & 115 & 2.91 \\
313 & 1.016 & 5.76 & 115 & 2.93 \\
406 & 1.036 & 5.70 & 116 & 2.95 \\
518 & 1.056 & 5.59 & 116 & 2.95 \\
\hline
\end{tabular}




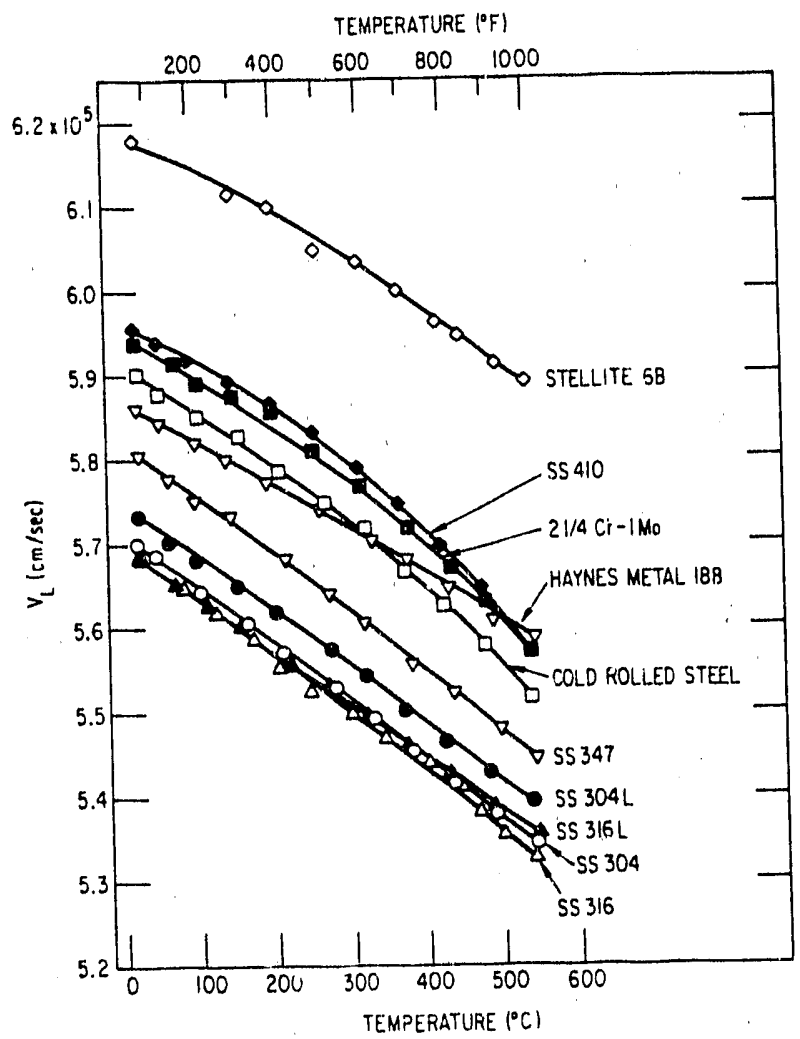

Fig. 15.

\section{Measured Ultrasonic Velocity Changes as a Function of Temperature for Various Metals}

\section{DISCUSSION AND CONCLUSIONS}

The investigation demonstrates the viability of two approaches to the construction of high-temperature ultrasonic erosion monitors. One of them, a pressure-coupling technique, was developed to the prototype stage and tested up to $500^{\circ} \mathrm{C}$. Recently, it has been shown that lithium niobate crystals can be brazed to stainless steel and the damping block requirement can be avolded when one of the crystal surfaces is shaped. Additional effort is required for both approaches. The design of the pressure-coupled transducers will need modification to compensate for coupling deterioration by the elongation of components at elevated temperatures. Protection of surfaces facing the crystal by coating with noble metals may be required for temperature cycling. Brazing of the insert (shoe) into a piece of sample tubing will require reforming of the tube to obtain a good fit and, subsequently, a good ultrasonic braze.

Air brazing of the crystal to an insert requires coating of the surface to prevent oxidation. as pointed out earlier in the text. The temperature range of the crystal-tube-insert braze will have to be assessed. Raising the brazing temperature of the tested experimental assembly to $850^{\circ} \mathrm{C}$ introduced a much higher noise level after cool-down. It should be established whether concave or convex shaping of one crystal surface would be more advantageous in deleting the damping block. It is anticipated that, from a coupling standpoint, the brazing method would be more advantageous than pressure coupling because it appears to be more stable.

\section{ACKNOWLEDGMENTS}

The author gratefully thanks E. Carls and W. Podolskd for their helpful encouragement and discussions. 


\section{REFERENCES}

1. C. A. Youngdahl and W. A. Ellingson, Nondestructive Monitoring of Erostve Wear at Synfuels Pilot Plants, Materials Performance 24(1), 48-5.3 (1985).

2. K. J. Reimann, Electromagnetic Acoustic Transducers (EMATs) for Erosion Monitoring, Argonne National Laboratory Report ANL/FE-84-12 (May 1984).

3. W. F. Podolski, K. J. Reimann, W. M. Swift, and E. L. Carls, Metal Wastage in Fluidized Bed Combustors, Proc. 10th Intl. Conf. on Fluidized Bed Combustion (1989, in press). 

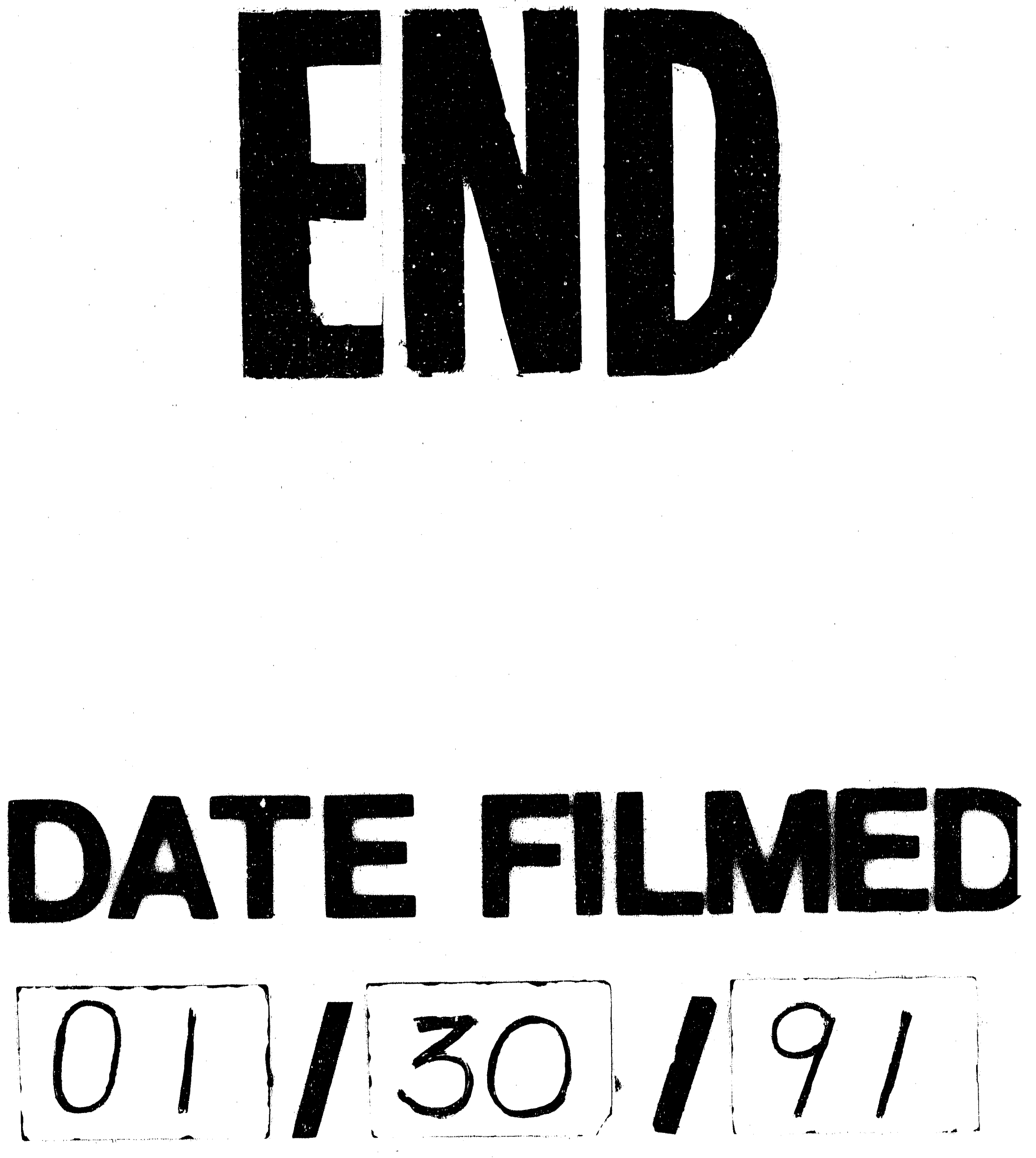
